\title{
Conversion of Vertical Banded Gastroplasty to Laparoscopic Gastric Bypass: a Step-By-Step Teaching Video
}

\author{
Jérémie Thereaux $^{1,2} \cdot$ Gaby Kansou $^{1} \cdot$ Bogdan Badic $^{1}$
}

Published online: 19 October 2015

(C) Springer Science+Business Media New York 2015

\begin{abstract}
Purpose Vertical banded gastroplasty (VBG) has been demonstrated to be disappointing for long-term weight loss and quality of life (Br J Surg 100:222-230, 2013). Laparoscopic revisional gastric bypass has been found to be feasible, but this procedure in case of prior VBG is deemed both challenging and difficult and should be performed by experienced surgeons (Obes Surg 22:1554-1561, 2012; Surg Endosc 27:558-564, 2013).

Materials and Methods We present the case of a 56-year-old man with a body mass index (BMI) of $39.6 \mathrm{~kg} / \mathrm{m}^{2}$ who had undergone open VBG, 11 years ago (initial BMI $39.2 \mathrm{~kg} / \mathrm{m}^{2}$ ). $\mathrm{He}$ was referred to our tertiary care center for weight regain and daily vomiting.

Results In this high definition multimedia video, we present a step-by-step laparoscopic conversion of VBG to gastric bypass. After careful adhesiolysis, key points of such procedure are resizing of the small gastric pouch and resection of the enlarged gastric pouch with the band and the upper portion of the remnant fundus, in order to avoid leakage or blind
\end{abstract}

Electronic supplementary material The online version of this article (doi:10.1007/s11695-015-1935-9) contains supplementary material, which is available to authorized users.

Jérémie Thereaux

jeremie.thereaux@chu-brest.fr

1 Department of General, Digestive and Metabolic Surgery, La Cavale Blanche University Hospital, Boulevard Tanguy Prigent, 29200 Brest, France

2 University of Bretagne Occidentale (UBO), EA 3878 (GETBO), 22 Avenue Camille Desmoulins CS 93837-29238, Brest, France stomach pouch. No adverse outcomes occurred during the postoperative period.

Conclusion Laparoscopic conversion of previous open VBG to gastric bypass is a challenging procedure. Learning the key points of such procedure is mandatory to limit postoperative complications.

Keywords Bariatric surgery $\cdot$ Revisional procedure $\cdot$ Gastric bypass

Conflicts of Interest The authors declare that they have no competing interests.

Ethics Approval Informed consent was obtained from all individual participants included in the study. All procedures performed in studies involving human participants were in accordance with the ethical standards of the institutional and/or national research committee and with the 1964 Helsinki declaration and its later amendments or comparable ethical standards.

\section{References}

1. Werling M, Fandriks L, Bjorklund $\mathrm{P}$, et al. Long-term results of a randomized clinical trial comparing Roux-en-Y gastric bypass with vertical banded gastroplasty. Br J Surg. 2013;100(2):222-30.

2. Suter M, Ralea S, Millo P, et al. Laparoscopic Roux-en-Y gastric bypass after failed vertical banded gastroplasty: a multicenter experience with 203 patients. Obes Surg. 2012;22(10):1554-61.

3. Apers JA, Wens C, van Vlodrop V, et al. Perioperative outcomes of revisional laparoscopic gastric bypass after failed adjustable gastric banding and after vertical banded gastroplasty: experience with 107 cases and subgroup analysis. Surg Endosc. 2013;27(2):558-64. 